\title{
ONLINE BASED NUTRITION EDUCATION: FOOD SAFETY QUIZ FOR ADOLESCENTS
}

\author{
Wardina Humayrah $^{1 *}$, Hardinsyah Hardinsyah ${ }^{2}$, Aviani Harfika $^{3}$, Septian Suhandono $^{4}$ \\ ${ }^{1}$ Nutrition Study Program, Sahid University Jakarta, ${ }^{2}$ Community Nutrition Department, Bogor Agricultural \\ University, ${ }^{3}$ Food and Nutrition Society of Indonesia, ${ }^{4}$ Linisehat.com \\ *wardina_humayrah@usahid.ac.id
}

\begin{abstract}
Nowadays, online based nutrition education can be more efficient way in the digital era while the people regularly used mobile sites for updating the information. This program aims to educate adolescent on food safety and balanced nutrition as well as to measure the effectiveness through online based quiz. This program was named "Food Safety Quiz via Online (FOSQO)", which held for four months divided into 8 terms and targeted on teenagers and young-adults (17-35 yrs old). The quiz in each term contained 20 questions regard food safety and balanced nutrition using online forms that available on the website page of Linisehat.com. The results showed that FOSQO had registered 595 adolescents including 303 actual participants. The mean nutrition knowledge score of the eight terms was $58 \pm 18$ and the mean length of time spent to answer the questions was $215 \pm 39$ seconds. The mean nutrition knowledge score of the 8 terms for the winners was $85 \pm 8$ and the mean length of time spent to answer the questions was $194 \pm 45$ seconds. The score of nutrition knowledge among participants who join the quiz repeatedly was rising $21 \pm 14$. Online based nutrition education of FOSQO could be an effective option to reach more millennial for improving their curiosity on gathering information of food safety and balanced nutrition.
\end{abstract}

Keywords: Adolescent, digital era, food safety, nutrition education, online based

\section{INTRODUCTION}

Lately, food safety policies, programs and studies are increasingly becoming the attention of various parties. Without safe food, it is impossible for the nutrients contained in it to be utilized by the body for healthy living (Tehet al. 2016). Besides that, since February 25, 2014, the Ministry of Health of the Republic of Indonesia has launched a Balanced Nutrition Guidelines (BNG). Three of the 10 BNG messages related to food safety, namely: 7th message (get used to drinking enough and safe water), 8th message (get used to reading labels on food packaging), and the 9th message (hand washing with soap through running water).Adolescence is a critical time for interventions to prevent malnutrition, a double and growing burden (Save the Children 2015). Dietary behaviours established in adolescence may contribute to nutrition-related problems that have consequences for long-term health. Beside that, the rapid growth and development which adolescents experience puts them at risk of micronutrient deficiencies (Lassiet al. 2015).Adolescents are actively engaged in learning through through school, course, mass media, etc (UNICEF 2011).

The digital era were driving a new nutrition education channel. The extend access through gadget make people used to online channel via website, social media and mobile application. Online based nutrition education was a new promising channel and it has been shown to be as or more effective than traditional nutrition education program (Lohseet al. 2013). As online based nutrition education opportunities emerge, recruitment strategies using social networks may facilitate the outcome and impact evaluation (Loehmeret al. 2016). The Food Safety Quiz via Online (FOSQO) was created to improve food safety and balanced nutrition knowledge among millennial. However, there were limited program with significant outcome measured of online and social media platforms for nutrition education, except FOSQO did. 


\section{THEORETICAL FRAMEWORK}

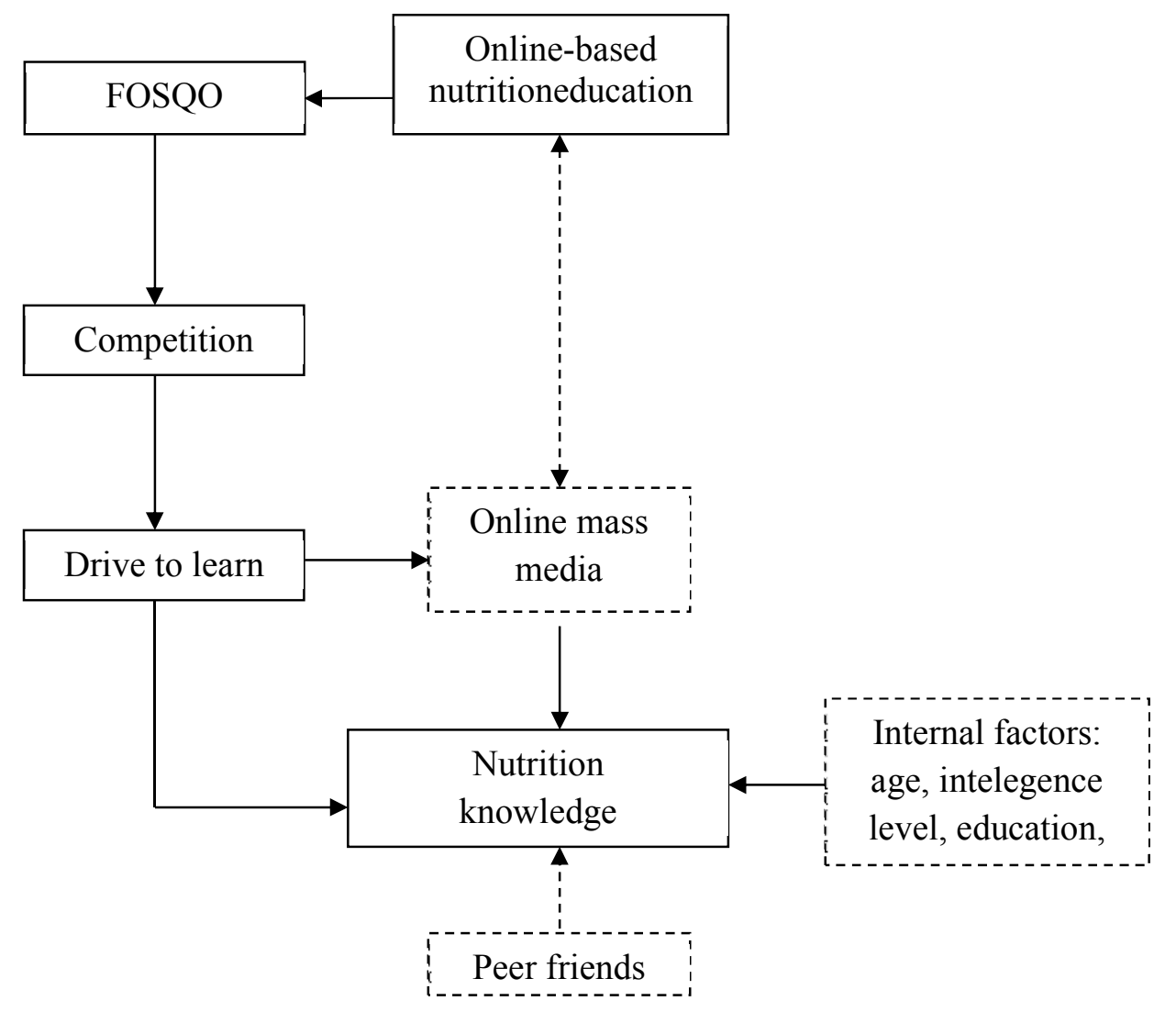

Figure 1. Theoretical framework of Online-based nutrition education

\section{METHOD}

\section{Participants and Mechanisms}

The target of FOSQO was teenagers and young-adults at aged 17-35 years old. FOSQO was divided into 8 terms with one winner for each term. It was held in four months from August to November 2017. It provided food safety and balanced nutrition quiz which was contained 20 multiple choice questions regard food safety and balanced nutrition using online forms that available on the website page of Linisehat.com. There were five steps to join FOSQO. Firstly, online registration that linked to Linisehat.com. Then, the participants received automatic reply in their email regard the link, date, and time of the quiz. After that, The link for quiz questions will be sent via email which is entered into the registration form at the specified time. Then, winners announced via the link linisehat.com/fosqo according to the specified date. Last, the distribution of prizes for the winners by attaching proof of identity during registration.

\section{Terms and Conditions}

There were 9terms and conditions of FOSQO. First, the quiz is open to the public and various professions with diverse backgrounds can take part in this quiz. Second, the participants were individuals and free charged during the registration process. Third, the requirementsto enter the competition were to fill out the registration form first in the online form. Fourth, the participants were required to like fanpage Lini sehat and PERGIZI PANGAN, follow@linisehat and @pergizi twitter and follow Instagram @linisehat and @pergizi. Fifth, participants worked on the quiz can start from 
when the link has been sent until the quiz filling time is up. Sixth, there is a deadline for filling in 20 quiz questions, the quiz will be closed if it has exceeded the time limit provided (4 minutes).Seventh, the participants who have not succeeded in the current term, can register in the next term. Eighth, the winners are the people who answer the questions correctly in the shortest possible time and if there are more than one person with the same value, the winner will be drawn by the committee.

\section{RESULT AND DISCUSSION}

The results showed that the FOSQO had registered 595 adolescents, and it was including 303 actual participants (Table 1). Each terms has various number participants, scores, and length of time spents. Overall, the mean nutrition knowledge score of the 8 terms was $58 \pm 18$ and the mean length of time spent to answer the questions was $215 \pm 39$ seconds. The highest number of participants and scores and the fastest length of time spentswas in $4^{\text {th }}$ term compare to other terms. However, the highest mean nutrition knowledge score was $64 \pm 14$ and the fastest length of time spents was $206 \pm 36$.

Table 1. The number of participants, mean of nutrition knowledge scores, and the length of time spents

\begin{tabular}{cccc}
\hline Terms & $\mathrm{n}$ & $\begin{array}{c}\text { Scores } \\
\text { mean } \pm \text { SD }\end{array}$ & $\begin{array}{c}\text { Time spents(seconds) } \\
\text { mean } \pm \text { SD }\end{array}$ \\
\hline 1 & 43 & $58 \pm 20$ & $219 \pm 40$ \\
2 & 40 & $52 \pm 18$ & $223 \pm 32$ \\
3 & 41 & $61 \pm 17$ & $227 \pm 24$ \\
4 & 44 & $64 \pm 14$ & $206 \pm 36$ \\
5 & 29 & $57 \pm 19$ & $219 \pm 30$ \\
6 & 39 & $59 \pm 17$ & $211 \pm 43$ \\
7 & 42 & $55 \pm 17$ & $212 \pm 46$ \\
8 & 25 & $57 \pm 24$ & $196 \pm 52$ \\
Total & 303 & $58 \pm 18$ & $215 \pm 39$ \\
\hline
\end{tabular}

Table 2 shows that the mean nutrition knowledge and the length of time spent to answer the quizamong the winners was far from than others participants. The highest quiz's scores of the winners was in $1^{\text {st }}$ and $6^{\text {th }}$ term while the fastest length of time spent to answer the quiz was in $4^{\text {th }}$ term. The winners was credible to answer the quiz appropriately and quickly.According to Khomsan (2004), nutrition knowledge score divided into three category namely: good $(>80)$; moderate $(60-80)$; and poor $(<60)$. Overall, the score of nutrition knowledge among the FOSQO's participants categorize as a poor while the lowest score of the winners still remain in moderate level. This indicate that most of adolescents still need nutrition knowledge improvement.

However, the FOSQO program gave a cash prize in each term as many as Rp. 500.000,00. This prize was be able as a curiosity trigger to collect nutrition knowledge for the participants to answer the quiz. This program allowed participants to join the quiz in many terms in order to improve their curiosity to win competition. Table 3 shows that there are 53 participants who were joining more than one term. Most of them were improving their nutrition knowledge score, the score was rising around 20 points after the first time joined. Beside that, there were participants who joined the quiz till six times.

Table 2. The mean of nutrition knowledge scores, and the length of time spents of the winners

\begin{tabular}{crr}
\hline Terms & Scores & Time spents (seconds) \\
\hline 1 & 95 & 219 \\
2 & 75 & 240 \\
3 & 85 & 199 \\
4 & 90 & 134 \\
5 & 85 & 240 \\
6 & 95 & 123 \\
7 & 80 & 218 \\
8 & 75 & 180 \\
Mean \pm SD & $85 \pm 8$ & $194 \pm 45$ \\
\hline
\end{tabular}


The proportion of participants who have improvement score were higher than the sagging ones. This implies that the online based nutrition education such as Food Safety Quiz via Online (FOSQO) had a significant result in enhancing the enthusiasm of finding nutrition information and upgrading nutrition knowledge among the participants.

Graciaet. al. (2013) said that the competitiveness able to enhance self-evaluation process - that was, how people evaluate their present state relative to others. The FOSQO program can compete each participants to get higher score as fast as possible. Furthermore, the participants had bigger motivation to learn more from the past so that they try to achieve more score and win in the next term. The other study using online quiz intervention showed that subject who joined had potential behavior changes related to the topics and this program was efficient and effective to improve nutritional knowledge (Belogianniet al. 2018).

Table 3. The improvement of nutrition knowledge among participants who joined the quiz more than once

\begin{tabular}{|c|c|c|c|c|c|c|c|c|}
\hline Participants & 1 & 2 & 3 & 4 & 5 & 6 & $\Delta$ Last - first & $\mathrm{n}$ Repetition \\
\hline 1 & 30 & 60 & 85 & - & - & - & 55 & 3 \\
\hline 2 & 30 & 75 & 90 & 55 & 75 & - & 45 & 5 \\
\hline 3 & 15 & 55 & 45 & 55 & - & - & 45 & 4 \\
\hline 4 & 5 & 50 & 50 & 55 & - & - & 45 & 3 \\
\hline 5 & 45 & 65 & 80 & 55 & 85 & - & 40 & 5 \\
\hline 6 & 40 & 50 & 70 & 55 & 75 & 75 & 35 & 6 \\
\hline 7 & 30 & 45 & 50 & 55 & 65 & - & 35 & 5 \\
\hline 8 & 35 & 70 & - & 55 & - & - & 35 & 2 \\
\hline 9 & 45 & 65 & 75 & 55 & - & - & 30 & 4 \\
\hline 10 & 20 & 40 & 50 & 55 & - & - & 30 & 3 \\
\hline 11 & 35 & 70 & 65 & 55 & - & - & 30 & 3 \\
\hline 12 & 40 & 70 & - & 55 & - & - & 30 & 2 \\
\hline 13 & 70 & 100 & - & 55 & - & - & 30 & 2 \\
\hline 14 & 40 & 75 & 65 & 55 & - & - & 25 & 3 \\
\hline 15 & 70 & 65 & 80 & 55 & - & - & 20 & 4 \\
\hline 16 & 55 & 60 & 75 & 55 & - & - & 20 & 3 \\
\hline 17 & 45 & 65 & - & 55 & - & - & 20 & 2 \\
\hline 18 & 55 & 75 & - & 55 & - & - & 20 & 2 \\
\hline 19 & 50 & 65 & 70 & 55 & 95 & - & 15 & 5 \\
\hline 20 & 40 & 55 & 55 & 55 & - & - & 15 & 3 \\
\hline 21 & 45 & 85 & 60 & 55 & - & - & 15 & 3 \\
\hline 22 & 45 & 60 & - & 55 & - & - & 15 & 2 \\
\hline 23 & 30 & 45 & - & 55 & - & - & 15 & 2 \\
\hline 24 & 80 & 95 & - & 55 & - & - & 15 & 2 \\
\hline 25 & 60 & 75 & - & 55 & - & - & 15 & 2 \\
\hline 26 & 55 & 70 & 75 & 55 & 75 & 65 & 10 & 6 \\
\hline 27 & 60 & 70 & - & 55 & - & - & 10 & 2 \\
\hline 28 & 55 & 65 & 50 & 55 & - & - & 5 & 4 \\
\hline 29 & 70 & 70 & 75 & 55 & - & - & 5 & 3 \\
\hline 30 & 50 & 55 & - & - & - & - & 5 & 2 \\
\hline 31 & 55 & 60 & - & 55 & - & - & 5 & 2 \\
\hline 32 & 55 & 60 & - & 55 & - & - & 5 & 2 \\
\hline 33 & 65 & 70 & - & 55 & - & - & 5 & 2 \\
\hline 34 & 30 & 35 & - & 55 & - & - & 5 & 2 \\
\hline 35 & 75 & 80 & - & 55 & - & - & 5 & 2 \\
\hline 36 & 70 & 75 & - & 55 & - & - & 5 & 2 \\
\hline 37 & 65 & 65 & 75 & 55 & - & - & 0 & 4 \\
\hline 38 & 35 & 35 & - & 55 & - & - & 0 & 2 \\
\hline 39 & 70 & 70 & - & 55 & - & - & 0 & 2 \\
\hline 40 & 85 & 65 & 55 & 55 & - & - & -5 & 4 \\
\hline
\end{tabular}




\begin{tabular}{|c|c|c|c|c|c|c|c|c|}
\hline Participants & 1 & 2 & 3 & 4 & 5 & 6 & $\Delta$ Last - first & $\mathrm{n}$ Repetition \\
\hline 41 & 65 & 60 & - & 55 & - & - & -5 & 2 \\
\hline 42 & 70 & 65 & - & 55 & - & - & -5 & 2 \\
\hline 43 & 65 & 60 & - & 55 & - & - & -5 & 2 \\
\hline 44 & 45 & 55 & 55 & 55 & - & - & -10 & 4 \\
\hline 45 & 65 & 55 & - & 55 & - & - & -10 & 2 \\
\hline 46 & 85 & 75 & - & 55 & - & - & -10 & 2 \\
\hline 47 & 80 & 70 & - & 55 & - & - & -10 & 2 \\
\hline 48 & 95 & 85 & - & 55 & - & - & -10 & 2 \\
\hline 49 & 55 & 65 & 45 & 55 & - & - & -15 & 4 \\
\hline 50 & 85 & 75 & 70 & 55 & - & - & -15 & 3 \\
\hline 51 & 60 & 45 & - & 55 & - & - & -15 & 2 \\
\hline 52 & 80 & 65 & 45 & 55 & - & - & -20 & 4 \\
\hline 53 & 60 & 35 & - & 55 & - & - & -25 & 2 \\
\hline \multicolumn{5}{|c|}{ Score of Nutrition Knowledge ( $\Delta$ Last - first) } & $\mathrm{n}$ & $\%$ & Mean & SD \\
\hline \multicolumn{5}{|l|}{ Increase } & 36 & 67.92 & 21 & 14 \\
\hline \multicolumn{5}{|l|}{ Stable } & 3 & 5.66 & 0 & 0 \\
\hline \multicolumn{5}{|l|}{ Decrease } & 14 & 26.42 & -11 & 6 \\
\hline
\end{tabular}

\section{CONCLUSION}

Online based nutrition education of Food Safety Quiz via Online (FOSQO) could be an effective option to reach more millennial for improving their curiosity on gathering information of food safety and balanced nutrition. Considering most of millennial used android for online access, the online based nutrition education such as FOSQO is promising method for disseminating nutrition and food safety information for millennial.

\section{ACKNOWLEDGEMENT}

Thank you very much to PT Ajinomoto Indonesia for supporting this program; and thanks also goes to MaulidDoniRahman for his technical support.

\section{REFERENCES}

Belogianni, A., Ooms, A., Ahmed, A., Nikoletou, D., Grant, R., Makris, F., \&Moir, H.J. (2018). Rationale and Design of an Online Educational Program Using Game-Based Learning to Improve Nutrition and Physical Activity Outcomes Among UniversityStudents in the United Kingdom, Journal of the American College of Nutrition, DOI: 10.1080/07315724.2018.1476929. ISSN: 0731-5724.

Garcia, S. M., Tor, A., \& Schiff, T. M. (2013). The psychology of competition: A social comparison perspective. Perspectives on Psychological Science, 8(6), 634-650.

Khomsan, A. (2004). PangandanGiziuntukKesehatan. Jakarta (ID): PT Raja GrafindoPersada.

Lassi, Z. S., Salam, R. A., Das, J. K., Wazny, K., \&Bhutta, Z. A. (2015, August). An unfinished agenda on adolescent health: opportunities for interventions. In Seminars in perinatology (Vol. 39, No. 5, pp. 353-360). WB Saunders.

Loehmer, E., Smith, S., \& McCaffrey, J. (2016). Internet Access and Interest in Online Nutrition Education Among SNAP-Ed Participants in Southern Illinois. Journal of Nutrition Education and Behavior, 48(7), S55.

Lohse, B. (2013). Facebook is an effective strategy to recruit low-income women to online nutrition education. Journal of nutrition education and behavior, 45(1), 69-76. 
[MoH] Ministry of Health Republic of Indonesia.(2014). Indonesia Dietary Guideline 2014. Ministry of Health : Jakarta.

Save the Children. (2015). Adolescent Nutrition. London (UK): The Save the Children Fund.

Teh, N. S. A., Ab Hamid, M. R., Asmawi, U. M. M., \&Nor, N. M. (2016). Food Hygiene's Knowledge, Attitudes and Practices between Urban and Suburban Adolescents. Procedia-Social and Behavioral Sciences, 234, 36-44.

UNICEF. (2011). The state of the World's children 2011: adolescence-an age of opportunity. New York (US): United Nations Children's Fund. ISBN: 978-92-806-4558-3. 